\title{
Fotografias Co-Produzidas da Situação de Trabalho: imagens em ato da atividade em saúde
}

\section{Co-produced photographs of the work situation: images in the act of activity in health}

\begin{abstract}
Resumo:
Neste artigo discutimos a complexidade relacional que é o trabalhar em saúde, com forte prescrição sobre a subjetividade e um possível dispositivo para a análise desta atividade. Em seguida, aproximando Yves Clot, Gilles Deleuze e Félix Guattari, enfatizamos a atividade laboral como um processo no qual emergem, ao mesmo tempo, trabalhador e trabalho em um plano de atravessamento heterogêneo de forças. Ao final, analisamos a Oficina de Fotos, conforme efetivada por nossa equipe de pesquisa, como um dispositivo potente de uso da experiência como fonte de novas experiências, redescobrindo a atividade, deslocando o pesquisador e o pesquisado de seus lugares instituídos, o que amplia o poder/saber de ambos e instrumenta uma nova ferramenta para a análise das atividades de trabalho, dando ênfase à pesquisa da subjetividade conforme instrumentada na ação.

Palavras-chaves: Trabalho. Atividade. Subjetividade. Dispositivo. Análise do Trabalho.

\section{Abstract:}

The relational complexity that working in health is, with strong precept on subjectivity, and a possible instrument of analysis of this activity are discussed in this article. After that, approaching Yves Clot, Gilles Deleuze and Félix Guattari, we emphasize labor activity as a process in which emerge, simultaneously, worker and work in a heterogenetic plane of crisscrossing forces. At the end, we analyze the Photography Workshop, as performed by our research team, as a potent instrument of use of experience as source of new experiences, rediscovering the activity, dislocating the researcher and research from their conventional places, which amplifies the power/knowledge of both, and instruments a new tool for the analysis of work activities, emphasizing research of subjectivity as instrumented in action. Keywords: Work. Activity. Subjectivity. Instrument. Analysis of work.
\end{abstract}

OSORIO, Claudia ; MAIA, Miguel. Fotografias Co-Produzidas da Situação de Trabalho: imagens em ato da atividade em saúde. Informática na Educação: teoria \& prática, Porto Alegre, v. 13, n. 2, p. 46-54, jul./dez. 2010.

\author{
Claudia Osorio \\ Universidade Federal Fluminense \\ Miguel Maia \\ Universidade Federal do Rio de Janeiro
}

\section{Introdução}

50 ste artigo discute a atividade em saúde e o uso de dispositivos que possam mediar a pesquisa coletiva do trabalho que aí se realiza, privilegiando nesta análise o ponto de vista da atividade. O dispositivo tomado neste debate usa a imagem - a fotografia que tem como objeto situações de trabalho - como um texto que fala do trabalho, ao mesmo tempo em que provoca novos diálogos sobre a atividade laboral, utilizando a experiência como fonte de novas experiências.

Militando na área de saúde, os autores entendem que o trabalhar nestes serviços é defrontar-se com uma realidade complexa na qual se evidencia o fator coletivo, presente em todo trabalho. Por atuarem na prestação de serviços, estes trabalhadores ressentem no cotidiano um acréscimo daquilo que já era característica do setor e que Lazzarato e Negri (2001) denominam como a reformulação produtiva da atualidade, a assunção do trabalho imaterial, com tendência a tornar-se hegemônico, na qual a cooperação, a comunicação e a subjetividade são prescrições imperiosas.

A exigência de engajamento total, que conclama a alma do trabalhador a descer no chão 
da fábrica (NEGRI, 2001), prescreve fortemente a autonomia, a cooperação, a flexibilidade e a inventividade no trabalho, sem, contudo, oferecer em contraparte aquilo mesmo que tornaria possível esta prescrição: a co-gestão nos processos decisórios, na organização e na divisão do trabalho.

Desta forma, cria-se uma situação em que o trabalhador é incitado a se envolver integralmente e, ao mesmo tempo, dosar este engajamento para que não ultrapasse os limites prescritos, raramente com clareza, em que sua inventividade ameace o ordenamento de uma produção que segue capitalista. A premente prescrição da subjetividade tem um efeito deletério, que mal começamos a compreender, por vir fortemente atrelada a uma proscrição de interferência nos critérios instituídos de gestão.

Esta subjetividade, ao mesmo tempo prescrita e proscrita, com a exigência de uma autonomia que, ao final das contas é negada, entendemos como aquilo que Yves Clot (2006), na França, cunha como a amputação da ação, caracterizando-a como a desrealização do trabalho no contemporâneo. O trabalhador se sente então obrigado a assumir responsabilidades, sem ter responsabilidade efetiva na gestão do trabalho. Abandonado pela gestão e incitado a resolver os conflitos do real, na linha de ponta, sem nenhuma autonomia para efetivar esta ação, chamado a se envolver integralmente no trabalho e impedido de trabalhar, é que ele, apesar dos pesares, segue produzindo.

\section{Linha de Produção do Cuidado: o trabalho vivo em ato}

Onde quer que esteja localizado na linha de produção da máquina do cuidado, o trabalhador é atravessado por todo tipo de pressão, uma vez que, além daquelas oriundas de uma noção de hospital como empresa, tônica que incide sobre o modelo de gestão dos serviços no contemporâneo, tem ainda que lidar com um objeto vivo de trabalho: o usuário.

Assim, gestores, trabalhadores e usuários, contextualizados nessa sociedade midiática que, se não contribui com sua autonomia política, não deixa de inculcar-lhes valores e expectativas de como e em que lugar existe um bom atendimento em saúde, levam para seu encontro desejos, interesses e necessidades que podem gerar conflitos no relacionamento, por não partilharem da mesma compreensão, enquanto protagonistas, do serviço que deve ou pode ser produzido.

No contexto dos serviços públicos de saúde, este usuário já chega com uma visão desacreditada de quem e de qual oferta de cuidado será produzida, o que não deixa de problematizar uma atividade que é centrada primordialmente no trabalho vivo em ato, como diz Merhy (2002), embasada prioritariamente nas tecnologias leves, isto é, no aspecto relacional "[...] particularmente forte e decisivo para a eficácia do ato [...]" (NOGUEIRA, 1997, p. 59), o que já nos fez (MAIA, 2006) definir o objeto em saúde como sendo, em primeiro lugar, o estabelecimento de uma relação política.

Diante de todas estas pressões a exigir constantes tomadas de decisões, o profissional de saúde, como acréscimo, ainda tem de lidar com uma atividade necessariamente fragmentada, cuja qualidade do produto final necessita de toda uma orquestração coletiva, em um meio no qual as formas de entender o cuidado, o corpo, a doença não são as mesmas.

Tal fragmentação, na qual não se evidencia o produto final senão em seu acabamento, faz com que o profissional trabalhe quase que diariamente com a possibilidade de erros, em uma atividade em que a presença destes pode ter conseqüências desastrosas, exigindo, portanto, uma carga extra de atenção e de defesas.

Além de tudo isto, na realidade dos serviços de saúde constatamos, em consonância com Baremblitt, como causas principais de deflagração de conflitos:

Os baixos salários, as más condições de trabaIho, a falta de instrumental adequado, a ausência de um plano de carreira, o excesso de demanda, a inadequada formação profissional ou específica, a carência de reciclagem periódica de conhecimentos, a concorrência não construtiva, a exigência de eficiência não sustentada, o autoritarismo, a verticalidade radical, assim como a liderança indiferente ou ausente, a falta de comunicação ou as distorções da mesma, a inexistência de uma atenção médica e psicológica permanente para os agentes e de uma consultoria periódica institucional para o estabelecimento [...] (BAREMBLITT, 2009, p. 1)

\subsection{A Atividade: produção de produção}

Percebemos, então, que o trabalhador de saúde tem sua subjetividade requisitada $\mathrm{o}$ 
tempo todo para atuar neste cenário, de cuja organização raramente participa, mas do qual deve dar conta, superando os conflitos do real, dificilmente cobertos por prescrições, mas que não deixam de exigir dele implicações e iniciativas, a fim de trabalhar.

Em um campo interacional tão complexo, de múltiplas conexões e exigências, a falta de um espaço/tempo que permita a construção comum do trabalho, sem dúvida, gera sentimentos de isolamento e insegurança. Sentimentos propícios a fazer emergir diversas formas de defesa que, se quiser trabalhar, ele terá que colocar em ação a fim de se proteger, de proteger as suas de outras intenções concorrentes e assim, finalmente, apesar dos pesares, levar a cabo suas atividades.

Referenciados neste contexto complexo é que nos aproximamos da Clínica da Atividade, conforme proposta por Yves Clot (2006), na França. Para este autor, com efeito, a atividade é muito mais do que a realização da tarefa, pois mobiliza plenamente aquele que trabalha em seus aspectos cognitivos, físicos e sociais, apresentando-Ihe um desafio interessante.

Tal desafio, obrigando-o a sair de si, é entendido por Clot (2006) como uma função psicológica importante, no sentido de referenciálo no mundo de tal forma que, ao trabalhar, aquele que se ocupa com a atividade está ao mesmo tempo se trabalhando, razão pela qual aproximamos o autor da concepção de Deleuze e Guattari (1972), quando postulam que a produção desejante é sempre uma produção de produção, ou seja, aquele que produz algo também é produzido no momento mesmo em que o produz.

Entendida desta forma, a atividade laboral engloba muito mais do que se supõe, já que envolve uma produção de subjetividade que, se quisermos entendê-la, exige do analista do trabalho o entendimento daquilo que se produz naquele que produz quando produzindo (MAIA, 2006), o que não se fará sem que efetivamente o trabalhador se torne um co-analista de seu próprio trabalho.

Esta aproximação entre os autores é tão mais pertinente porque, conforme entendemos, Yves Clot não corrobora com a equação trabaIho = sofrimento, pois o trabalhador não está completamente sujeitado ao prescrito, já que, referenciado no gênero da atividade ${ }^{1}$, ele tem

1 O gênero em Clot (2006) não se refere ao sexo, mas a de tomar decisões, protegendo a sua de outras intenções que atravessam a sua atividade.

A atividade laboral, assim, está sempre orientada para a sua própria ação, a ação sobre o objeto de trabalho e a ação sobre e dos outros trabalhadores, conectados com sua atividade. Este tripé si mesmo, objeto e outro é o que Clot (2006) entende como unidade de análise do trabalho e que faz com que a atividade nunca seja uma simples execução de tarefas, mas uma atividade inventiva, sujeita a escolhas, que o trabalhador tem de realizar, se quiser trabalhar.

\section{Co-Gestão: o imperativo da atividade laboral}

Este sentido forte do trabalho, como experiência e reinvenção de experiência através da própria experiência, torna o trabalhador um protagonista daquilo que faz, de forma que podemos afirmar que todo trabalhador é um co-gestor da atividade de trabalho.

Esta co-gestão, uma espécie de corpo invisível do trabalho (MAIA, 2006) conclamando a subjetivação, a cooperação social e a expressividade, é um imperativo de toda atividade. Mesmo que não reconhecida pelo trabalhador e ainda que dificultada pela desrealização da gestão no trabalho contemporâneo (CLOT, 2006), com metas fictícias e irreais, sob a pressão da rapidez, da segurança, da eficácia e da eficiência em um cenário de contração do espaço e do tempo, a co-gestão está sempre presente em toda atividade laboral.

Pois, desafiado a trabalhar, o trabalhador tem de dar conta dos diversos obstáculos do real, entre eles, o jogo das intenções que atravessa toda atividade que, como dissemos, está sempre voltada, ao mesmo tempo, para o objeto de trabalho, os outros e si mesmo.

Decorrente disto, a Clot (2006) interessa também a inibição da ação, que ele entende como parte mesmo do agir. Para realizar o trabalho é necessário selecionar dentre todos os

uma espécie de interposto social entre o trabalhador e o seu trabalho, conduzindo-o, sem necessidade de ensaio e erro, por meio de regras escritas e não escritas em seu meio de trabalho e o orientando nas relações sociais em suas atividades. Clot (2006) entende, referenciando-se em Bakhtin, que para trabalhar, da mesma forma que o escritor na área literária, o trabalhador utiliza-se de um gênero profissional que o orienta a respeito do que se deve e o que não se deve fazer no meio e nas relações de trabalho. 
possíveis aqueles que serão realizados, deixando de lado outros que, ainda que fazendo parte do desejo de realização, não são vistos pelo trabalhador situado em sua atividade como realizáveis.

Assim, a atividade engloba não somente o que se faz, mas também o que não se faz, o que se gostaria de fazer, o que não se pode fazer, o que se faz para não fazer o que se gostaria (CLOT, 2006), enfim, toda uma gama de atividade impedida que não desaparece simplesmente porque não está se realizando no momento, mas que se inibe para poder realizar um possível, tendo isto conseqüências para o trabalho.

Entendemos que a atividade situada tem em Clot este sentido forte que, de imediato, conclama a necessidade de subjetivação. Por isto Clot (2006) diz que a atividade tem uma história e, baseando-se na psicologia de Vygotsky, fala que é preciso entender o desenvolvimento da atividade.

\subsection{Co-Gestão: um plano complexo de forças}

Torcendo a teoria de Clot, embora entendamos que ele trabalhe com uma idéia ampliada de desenvolvimento, no sentido de evitar a noção de estágios que se sucedem naturalmente, de uma continuidade linear, já que na atividade há o atravessamento de vários planos ao mesmo tempo, que a tornam situada, preferimos nesse texto trabalhar com o conceito de processo, que descreveremos abaixo e que tomamos de empréstimo a Deleuze e Guattari (1972).

A atividade, para nós, é situada porque é uma concorrência de planos de consistências, ou seja, de várias formas possíveis de ação, dentro de um plano de forças complexo.

Diríamos então que, ao se aproximar deste plano, o trabalhador está já determinado pela sua atividade que, aliás, é o que socialmente o referencia como um trabalhador, isto é, aquele a quem é outorgado certo poder de fazer, por possuir um saber autorizado para efetivá-lo.

Situado por isto, que o determina a ser detentor de algumas técnicas, não só ele está prescrito pela organização do trabalho, como também proscrito de ultrapassar este poder que lhe é outorgado. Há em toda prescrição de atividade, portanto, uma proscrição. Diríamos, com Clot (2006), uma atividade inibida.
Inibida não só pela organização do trabalho, em seu sentido macro, mas também em seu sentido micro pela pertinência de todo trabaIhador a um gênero de atividade, isto é, a um conjunto de regras escritas e não escritas que Ihe prescrevem, agora informalmente, o que deve ser realizado, como deve ser realizado e as formas de trânsito por entre todos aqueles que realizam a mesma tarefa. Também o gênero da atividade tem sua dupla face.

Duplamente prescrito e proscrito é que o trabalhador se aproxima de sua atividade, atuando então como um tensor deste plano de ação que, se quiser funcionar, terá que tomar para si a decisão de efetuar, apesar dos pesares, o que deve ser realizado.

Tensionado e tensionando, não há como, frente ao objeto de trabalho e aos outros que possuem intenções concorrentes ou solidárias sobre este objeto, o trabalhador não voltar-se para si mesmo e, em um movimento de outrarse, criar uma maneira única de trabalhar que o caracteriza como uma singularidade em ação.

Singularidade que é uma estilização, habitando os limites de um gênero profissional e arrastando em um devir o próprio gênero, o conjunto do prescrito, inventando neste acontecimento, no sentido Deleuziano, sua atividade que o faz devir de trabalhador em um trabalhador. Se quisermos utilizar Ceccim \& Merhy (2009), de um ser particular que trabaIha em um ser singular que põe em ação um trabalhar.

Neste sentido, nos autorizamos a ultrapassar o conceito de desenvolvimento preferido por Clot (2006), para a noção de processo, pois é ao mesmo tempo em que devém um mundo em que, de um ser particular que está prescrito em uma atividade forçada, que é o trabalho, aparece um ser determinado, determinante e em determinação que diríamos, então, um trabalhador.

Co-gestor que aparece como trabalhador no momento mesmo em que é responsivo e responsável por uma atividade entendida como trabalho, na qual se espera a produção de algo determinado, tenha ele ou não necessidade deste produto.

\subsection{Co-Gestão e Sofrimento: a amputação da ação}

Neste sentido, o corpo invisível do trabalho pode ser entendido como uma subjetivação, uma corporização (MAIA, 2006), por se tratar, 
digamos assim, de tomar um plano de organização abstrato do trabalho e, na potência de outrar-se, gerir uma encarnação real, que é a atividade, em um processo em que singularização e coletivização se territorializam, desterritorializam e retorritorializam (DELEUZE; GUATTARI, 1972) em uma tensão constante.

Um trabalho vivo em ato passível ao mesmo tempo de capturas e descapturas, ou se quisermos, do que aumenta sua potência de vida e do que perturba esta potência, nesta heterogênese que se chama trabalho.

Assim, se começamos este artigo descrevendo a complexidade e dificuldade de se trabalhar em saúde, não foi com a intenção de naturalizar a situação, nem de postular uma espécie de adicional de miserabilidade para o trabalhador de saúde, mas apenas para enfatizar que, se os serviços de saúde funcionam e alcançam suas metas, diante desta precariedade e complexidade (MUNIZ, 2000), é porque há um corpo invisível do trabalho, uma subjetividade desejante que faz a máquina trabalhar.

Aproximando Clot (2006) de Deleuze e Guattari (1972), só a faz funcionar desarranjando-a. Pois é na estilização do gênero de trabalho, apropriando-se dele e a ele dando algo de seu, que a atividade se realiza, é no rearranjo do prescrito que toda atividade é levada a cabo, o que nos lembra Schwartz (2003) quando diz que o prescrito é invivivel.

O sofrimento psíquico no trabalho, conforme entendemos Clot, não tem uma correlação direta com a complexidade e os obstáculos da atividade, mas sim com o não reconhecimento disto que denominamos acima o corpo invisível do trabalho. Se o trabalhador sofre ao trabaIhar, é quando não se dá o tempo necessário para a mobilização do gênero profissional e, consequentemente, para a estilização deste. É por uma espécie de amputação da ação, de uma mobilização da subjetividade ao mesmo tempo prescrita e proscrita que se entra em sofrimento psíquico, ao exigir a atividade e impedi-la de se realizar.

Assim, buscar metodologias que ponham em foco este corpo invisível do trabalho, reconhecê-lo como um valor de uso, meio e fonte motriz da atividade, nos parece ser, principalmente na área de saúde, centrada prioritariamente no trabalho vivo em ato (MERHY, 2002), uma importante contribuição para o incremento da pesquisa na área de Saúde do Trabalhador. Pois nos parece ainda muito vaga a correlação entre o trabalho centrado em tecnologias leves (MERHY, 2002), isto é, nos aspectos relacionais, e os distúrbios que destas relações podem advir, quando o gênero e o estilo se acham desconjuntados e impedidos de serem mobilizados.

\section{Experimentando Metodologias}

Com foco neste tipo de reflexão é que os autores têm buscado metodologias capazes não só de dar visibilidade a esta dimensão subjetiva da atividade, como também engajar os trabalhadores neste movimento de pesquisa do seu próprio trabalho, por entenderem que toda intervenção na atividade é ao mesmo tempo produção de subjetividade.

Assim, em nossa concepção, a análise do trabalho toma este sentido forte de ser também um dispositivo de formação dos trabalhadores, não se constituindo tão somente em uma forma de extrair o saber daqueles que laboram para aumentar o nosso poder de compreensão e de intervenção na realidade do trabalho.

Intervenção e formação não mais se separam, uma vez que acreditamos que só transformando, ou seja, utilizando a experiência como fonte de novas experiências, é que tornamos potente o conhecer, na medida mesma em que fortalece o gênero da atividade e aumenta o poder de ação dos envolvidos na análise.

\subsection{Oficina de Fotos: um dispositivo de análise do trabalho}

O dispositivo de análise posto em prática por nosso grupo de pesquisa em um hospital público da cidade do Rio de Janeiro, denominado Oficina de Fotos (OSORIO, 2007, OSORIO et al., no prelo), aparece, conforme entendemos, com esta potência; fotografando os trabalhadores em ação ou armando-os com câmaras digitais ${ }^{2}$, solicitando que fotografem aquilo que consideram como fortalecendo a saúde no trabalho e aquilo que a enfraquece, tendo eles autonomia para a escolha do material a ser fotografado.

\footnotetext{
2 Acreditamos que o uso de câmaras digitais tem a praticidade da imediatez das fotos, facilmente transpostas para um computador, o que facilita a análise do trabalho, evitando interrupções e esperas.
} 
De posse das fotos, parte-se para uma discussão coletiva do material, ocasião em que, na experiência dialógica, os trabalhadores vão não só fazendo saber as suas atividades, mas, principalmente, as descobrindo e se descobrindo nelas, reformulando a maneira de se posicionar frente ao trabalho. Na posição de co-analistas eles se percebem como protagonistas e co-gestores do próprio trabalho, o que fortalece o poder de ação do coletivo.

Porém, importante ressaltar, acreditamos que as imagens cumprem este papel importante quando são entendidas como dispositivos. Desta forma, tanto nas oficinas de fotos acima citadas quanto no que entendemos das experiências com filmagens, descritas por Yves Clot, não se compreende a imagem como representação do real, no sentido de tomá-las como uma verdade de fato, como uma apreensão mais autêntica do que se produz, a despeito da observação do analista ou do que dizem os trabalhadores sobre aquilo que fazem.

\subsection{Dispositivo Imagem: o foco no desfocar}

Entendemos que, por vivermos em uma sociedade de controle, na qual tem se pulverizado os olhos do poder, utilizando-se, dentre outros, do artifício das câmaras, em uma suposta noção de segurança, possa a experiência com imagens gerar certa suspeita, no sentido de que poderia se tornar, ao final das contas, em mais um meio de controle sobre os trabalhadores, o que de fato é uma possibilidade, mas neste caso seria outro dispositivo, com o qual os autores não corroboram.

Mas o que queremos dizer com serem as imagens utilizadas como dispositivo? O que é um dispositivo? Damos a palavra a Deleuze:

É de início um novelo, um conjunto multilinear. Ele é composto de linhas de natureza diferente. Estas linhas no dispositivo não cercam ou não contornam os sistemas onde cada um seria homogêneo por conta própria, o objeto, o sujeito, a linguagem, etc. Mas seguem direções, traçam processos sempre em desequilíbrio, e ora se aproximando, ora se afastando uma das outras. Cada linha é quebrada, submetida às variações de direção, bifurcante e fendida, submetida às derivações. Os objetos visíveis, os enunciados formulados, as forças em exercício, os sujeitos em posição são como vetores ou tensores... Separar as linhas de um dispositivo, em cada caso, é construir um mapa, cartografar, medir a passos terras desconhecidas [...] (DELEUZE, 1988, p. 1)
Não utilizamos as imagens como se devessem apenas ser vistas, em uma posição de expectador passivo, em uma atitude de neutralidade, como se elas se manifestassem integralmente ao campo perceptivo, restando uma contemplação que, como uma câmara escura, retivesse impressa a cópia da realidade. A imagem, para nós, não funciona como a luz divina de uma realidade que se manifesta sem as sombras retinianas da percepção do olho humano, em uma evidência apodítica de um fato imutável e eterno, registro das idéias. Muito pelo contrário, ela é apenas uma via de passagem, um texto que deve ser lido em toda a sua polissemia, por isto, um dispositivo.

Para nós a imagem funciona, nestas experiências - oficina de fotos e filmagens em gravações de trabalho - não como o que se apresenta à vista, mas como o que se regateia a prazo, como uma compra que não advém de um desejo de consumo puro e simples, mas de uma ocasião de negociação, na qual a dívida não se faz pela aquisição do produto, a imagem, mas pela prestação de um contrato, o diálogo.

Dívida infinita, ao gosto do Capitalismo, mas o que se deve nela, infinitamente quanto possível, é o não fechamento para a sua manifestação de uma estranheza. A visão do trabalho como um susto (CLOT, 1993).

Susto porque o trabalhador, em um disposionamento, passa para o lugar desconhecido de quem se vê na ação, impossível de outra maneira. Ele é um si mesmo que se vê como um outro. Outramento que o faz perceber-se de uma forma diferente. Nas imagens ele pode ver, entre outras coisas, suas expressões, sua postura corporal, enfim, suas afetabilidades e descobrir-se como alguém que utiliza seu corpo como ferramenta de trabalho. As corporizações (MAIA, 2006) tornam-se visíveis.

Nestas ocasiões, não raro, eles descobrem outras possíveis fontes do trabalho. Começam a perceber que a subjetividade não é aquilo que está dentro dos seus corpos, mas um processo que se dá no corpo em ação, no encontro com outros corpos que são capazes de afetá-lo e que trabalhar é, então, uma maquinação biopolítica (MAIA, 2006) em que não há neutralidade possível, pois afetamos e somos afetados pelos objetos, pelos outros e por nós mesmos, posicionados, posicionantes e posicionando nesta unidade de análise do trabalho. 


\subsection{Do Dispositivo Imagem à Experiência Dialógica}

As imagens são utilizadas, então, como uma cartografia que, utilizando a experiência dialógica, vai levando o trabalhador para além do que ele costuma dizer de seu trabalho, para além do que ele convencionou em sua representação. A imagem não representa nada, ao contrário, ela apresenta um intempestivo, ela nos ajuda a criar uma linha de fuga do linguajeiro para a linguagem, entendida esta como expressividade de uma máquina biopolítica em ação (MAIA, 2006).

Utilizada desta maneira, temos experienciado o deslocamento do trabalhador para um lugar vazio. Vazio de representação, de clichês, de culpabilizações, de retóricas. Vazio de faltas, vazio do vazio.

Por não estarmos procurando o bom e o mau no trabalho, o que aperfeiçoa ou não a eficácia e a eficiência, mas estarmos focados sobre a atividade, em uma miopia foucaultiana de quem procura não o fundamento, mas a fundamentação da atividade - Clot diria a sua história -, inventa-se ali uma nova maneira de análise do trabalho. Cria-se uma rede em que os nós não se apertam em um nó cego, mas são nós que desobstaculizam a visão, outro regime de visibilidade, diria Foucault (2004), em que toda visão muito ampla desfoca e não permite ver, miopia, portanto. Pois é bem de perto, no diálogo que se entabula e confabula, que o trabalhador e o analista vão se deslocando para um plano de construção em que ninguém sabe o certo, mas sabe ao certo que um caminho se aponta para o saber.

Pois também uma linha de subjetivação é um processo, uma produção de subjetividade em um dispositivo: ela está para se fazer, na medida em que o dispositivo o deixe ou o torne possível. É uma linha de fuga. Escapa às outras linhas (a de poder e de saber), escapa-Ihes [...] É um processo de individuação que diz respeito a grupos ou pessoas, que escapa enquanto às forças estabelecidas como saberes constituídos: uma espécie de mais-valia. Não é certo que todo dispositivo disponha de um processo semelhante [...] São estas regras facultativas de orientação de si próprio que constituem uma subjetivação, autônoma, mesmo se esta é chamada, em conseqüência disso, a fornecer novos saberes e inspirar novos poderes. Podemos perguntar se as linhas de subjetivação não são o extremo limite de um dispositivo, e se não esboçam elas a passagem de um dispositivo a um outro: neste sentido, elas predispõem as linhas de fratura. (DELEUZE, 1988, p. 2-3)

\subsection{Diálogo: dispositivo de coletivização}

Temos experienciado que neste tipo de dispositivo o trabalhador utiliza o nós ao invés do eu, ele parece ser levado ao coletivo e a sentir-se parte de um coletivo em ação. As fotos ou filmagens parecem permitir uma repetição sem repetição, uma falar de uma ação que se repete todo dia, mas que não se repete na repetição de cada momento.

O trabalhador e o analista se dão conta então de um ritmo de trabalho em que cadências e acordes conhecidos fazem uma sinfonia diferente. Pois, insistimos, no trabalhar não há neutralidade possível (SANTOS FILHO; BARROS; GOMES, 2009), a sinfonia a que nos referimos pode ser tanto música (repetição sem repetição, potência, portanto), como ruído (repetição pura e simples, alienação da potência).

Os dispositivos têm por componentes linhas de visibilidade, linhas de enunciação, linhas de forças, linhas de subjetivação, linhas de brechas, de fissura, de fratura, que se entrecruzam e se misturam, acabando por dar uma nas outras, ou suscitar outras, por meio de variações ou mesmo mutações de agenciamento [...] É uma mudança de orientação que se desvia do Eterno para apreender o novo [...]

À novidade de um dispositivo em relação aos que o procedem chamamos atualidade de um dispositivo. O novo é o atual. O atual não é o que somos, mas aquilo em que nos vamos tornando, aquilo que somos em devir, quer dizer, o Outro, o nosso devir-outro [...] A história é o arquivo, é o desenho do que somos e deixamos de ser, enquanto o atual é o esboço daquilo em que vamos nos tornando. Sendo que a história e o arquivo são o que nos separa ainda de nós próprios, e o atual é este outro com o qual coincidimos desde já [...] (DELEUZE, 1988, p. 4-5)

Outro que coincide, então, com uma disposição de se disposionar no vazio, vazio intensivo, espaço/tempo para se permitir uma repetição sem repetição, uma experiência advinda da experiência de assumir a experiência como fonte de novas experiências. Neste sentido não mais história e arquivo, as imagens são utilizadas para a desestabilização do instituído, através da experiência dialógica, um agenciamento coletivo de enunciação para o devir-outro no estranhamento do que se repete. 


\section{Considerações Finais}

Em nossa pesquisa utilizando a fotografia o que queremos é desestabilizar o instituído, permitindo então que a experiência se abra para novas formas de poder, de saber e de subjetivar. Não prescrevemos a subjetividade do trabalhador, até porque, como dissemos, ela já está prescrita, mas problematizamos esta prescrição e este estar não como uma força apenas que assujeita, mas que também se abre a outras possibilidades. A descoberta dos possíveis da atividade é o que nos move. Ousamos repetir:

À novidade de um dispositivo em relação aos que o procedem chamamos atualidade de um dispositivo. O novo é o atual. $O$ atual não é o que somos, mas aquilo em que nos vamos tornando, aquilo que somos em devir, quer dizer, o Outro, o nosso devir-outro [...] A história é o arquivo, é o desenho do que somos e deixamos de ser, enquanto o atual é o esboço daquilo em que vamos nos tornando. Sendo que a história e o arquivo são o que nos separa ainda de nós próprios, e o atual é este outro com o qual coincidimos desde já $[\ldots]$ (DELEUZE, 1988, p. 6)

Atual que exemplificamos com uma única foto de nossa experiência, aquela que traz o susto de uma descoberta ${ }^{3}$.

Uma sala de descanso descoberta durante a experiência de fotografia, de que nem todos os trabalhadores enfocados conheciam a existência e/ou sabiam da possibilidade, gestando uma máquina desejante, mobilizando o coletivo para a obtenção deste importante espaço valorizado como o que aumenta a potência no trabalho.

Cômodo cair em tentativas de interpretação do lugar comum de que funcionário público não quer trabalhar, mas nem mesmo nos daremos ao trabalho de refutar isto. Tomamos a foto como um objeto parcial de uma máquina desejante, em seus múltiplos atravessamentos.

3 Optamos por não utilizar as fotos pelo seu caráter identitário, que não é o que buscamos. Interessa-nos o dispositivo em si, as fotos são parte da produção de um coletivo. Preferimos, então, discutir a experiência como um dispositivo potente, que fala por si, sem necessidade das imagens que possibilita. Estas serão novas a cada experiência e, pensamos, devem pertencer e continuar pertencendo ao coletivo que as gerou.

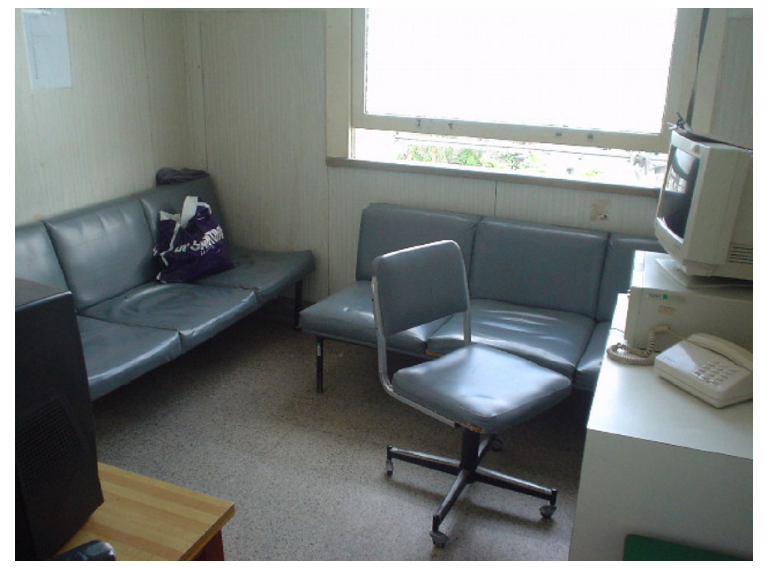

Desejo de parada em uma profissão estafante...

Lugar vazio a ser preenchido...

Possibilidade de encontros...

Linha de fuga do instituído...

Disposicionamneto da culpa...

Ícone de nossa proposta...

Convite ao leitor...

A inibição da ação faz parte da ação, como diz Clot (2006), uma vez que para agir temos de fazer escolhas, tomar decisões, antecipar, improvisar, enfim, realizar a tarefa. A atividade laboral assim, no dizer de Clot, tem uma história.

Acrescentaríamos, então, que esta história nos posiciona e determina a despeito de nós mesmos, exigindo-nos um disposicionamento, um descentramento, uma saída de si e um direcionamento para um não-si, que é o objeto do trabalho, os outros que se dirigem ao mesmo objeto, os outros para quem este objeto se destina e um outro que somos nós mesmos frente a este enigma que é o trabalho. Enigma porque, embora uma atividade forçada, é uma força que nos propulsiona, ao nos colocar frente a um desafio interessante, que mobiliza nossa subjetividade a ser engenhosa no engenho, tornando-nos plenos de sentido, ou, ao contrário, nos tornando uma máquina desastrada e desastrosa, alienada da produção de sentido e fazendo a potência sucumbir frente ao tédio e a impotência.

Assim, a modo de conclusão, diríamos com Santos-Filho, Barros e Gomes (2009), na esteira de Canguilhem, a atividade laboral não é neutra em termos de saúde, ou ela fortalece ou ela enfraquece nossa potência de vida. Por sermos seres normativos, cabe a nós, analistas do trabalho e co-analistas, os trabalhadores, reinventarmos a cada instante nossas atividades, impedindo-as de nos transformar em meros ciborgues de nós mesmos. 


\section{Referências}

BAREMBLITT, G. Conflitos e Malestares na Prática Hospitalar. Disponível em: <http://www.portalhumaniza. org.br/ph/texto.asp?id=36> Acesso em: 08 set. 2009.

CECCIM, R.B.; MERHY, E.E. Um Agir Micropolítico e Pedagógico Intenso: a humanização entre laços e perspectivas. Interface: Comunicação, Saúde e Educação, São Paulo, v. 3, supl. 1, p. 541-542, 2009.

CLOT, Y. A Função Psicológica do Trabalho. Petrópolis: Vozes, 2006.

CLOT, Y. Le travail comme source d'étonnement. Multitudes: Revue politique, artistique e philosophique, Paris, mars 1993. Disponível em: <http://multitudes.samizdat.net/spip.php?page=imprimer\&id_article=646> Acesso em: 14 set. 2009.

DELEUZE, Gilles. Qu'est-ce qu'un disposif? IN Michel Foucault philosophe. Rencontre internationale. Paris 9, 10, 11 janvier 1988. Paris, Seuil. 1989. Tradução de Ruy de Souza Dias.

DELeuZE, G.; GuATTARI, F. O Anti-Édipo, Capitalismo e Esquizofrenia. Rio de Janeiro: Imago, 1972.

FOUCAULT, M. Vigiar e Punir. Petrópolis: Vozes, 2004.

LAZZARATO, M.; NEGRI, A. Trabalho Imaterial. Rio de Janeiro: DP\&A, 2001.

MAIA, M.A.B. O Corpo Invisível do Trabalho: cartografia dos processos de trabalho em saúde. 2006. Dissertação (Mestrado em Psicologia) - Instituto de Ciências Humanas e Filosofia, Universidade Federal Fluminense, 2006, Niterói, BR-RJ.

MERHY, E.E. Saúde: a cartografia do trabalho vivo. São Paulo: Ed. Hucitec, 2002.

MUNIZ, H.P. A Gestão do Tempo de Permanência do Paciente de Neurocirurgia no Hospital Universitário Clementino Fraga Filho. 2000. Tese (Doutorado) - Curso de Pós-Graduação em Engenharia de Produção, Universidade Federal do Rio de Janeiro, 2000, Rio de Janeiro, BR-RJ.

NOGUEIRA, R.P. O Trabalho em Serviços de Saúde. Texto de apoio de Unidade Didática I. In: SANTANA, J.P. (Coord.). Desenvolvimento Gerencial de Unidades Básicas do Sistema Único de Saúde (SUS). Brasília: OPAS/ OMS, 1997. P. 59-63. Disponível em: <http//www.opas.org.br/Rh/publicações/textos_apoio/Texto_3.pdf> Acesso em: 16 set. 2009.

OSORIO, C. Trabalho e Perspectivas Clínicas. In: COLÓQUIO INTERNACIONAL DE PSICOSSOCIOLOGIA E SOCIOLOGIA CLÍNICA, 11., 2007, Belo Horizonte. Anais. Disponível em: <www.fafich.ufmg.br/coloquio/horarios.php> Acesso em: 16 set. 2009.

OSORIO, C.; PACHECO, A.B.; GARRÃO, J.M.G. Psicologia do Trabalho e Saúde do Trabalhador: desafios metodológicos. No prelo pela EDUFF.

SANTOS FILHO, S.B.; BARROS, M.E.B.; GOMES, R.S. A Política Nacional de Humanização Como Política que se faz no Processo de Trabalho em Saúde. Interface: Comunicação, Saúde e Educação, São Paulo, v. 3, supl. 1, p. 603-613, 2009.

SCHWARTZ, Y. Travail et gestion: niveaux, critéres, instances. Revue Performances Humaines et Technicque, Paris, n. Hors-série, p .10-20, sept. 2003.

Recebido em março de 2010.

Aprovado para publicação julho de 2010.

\section{Claudia Osorio}

Doutora em Saúde Pública pela ENSP/Fiocruz. Professora do Departamento de Psicologia e do Programa de Pós Graduação em Psicologia da Universidade Federal Fluminense. Niterói-RJ/Brasil.

Email: claudiaosorio@terra.com.br

\section{Miguel Maia}

Mestre em Psicologia pela Universidade Federal Fluminense, Psicólogo do Trabalho e membro do Núcleo de Humanização do Instituto de Puericultura e Pediatria Martagão Gesteira na Universidade Federal do Rio de Janeiro.

Email: miguel.maia@terra.com.br 